\title{
Concrete Retrofitting Using CFRP and Geopolymer Mortars
}

\author{
Eduardo Vasconcelos ${ }^{1, a}$, Sérgio Fernandes ${ }^{2, b}$, Barroso de Aguiar ${ }^{3, c}$ \\ F.Pacheco-Torgal ${ }^{4, d}$ \\ ${ }^{1234}$ Research Unit C-TAC, Sustainable Construction Group, University of Minho, \\ Guimarães, Portugal \\ ae.vasconcelos@net.cabo.pt, 'bsdanielfernandes@gmail.com, caguiar@civil.uminho.pt, \\ dorgal@civil.uminho.pt
}

Keywords: Geopolymers; CFRP; metakaolin; concrete retrofitting, adhesion strength

\begin{abstract}
A new development in the repair and strengthening of reinforced concrete systems is the use of carbon fiber reinforced polymers (CFRP) strips bonded to concrete substrate with epoxy resins. It has been reported that epoxy adhesive are extremely sensitive to high temperatures. Some authors conclude that the epoxy temperature should not exceed $70{ }^{\circ} \mathrm{C}$ in order to safeguard the adhesiveness of the epoxy and, thus, the integrity and adequate functioning of CFRP. It is noted that even frequently exposure to direct sunlight causes temperatures higher than $70{ }^{\circ} \mathrm{C}$. Since geopolymers are known to possess high stability at high temperature, these materials can be an alternative to epoxy resins.

This papers presents results about the use of metakaolin based geopolymers mortars to insure the adhesion between the CFRP and the concrete substrate. Several compositions of geopolymer mortars were executed by varying the percentage of binder, sand/binder ratio and the concentration of sodium hydroxide. It was found that geopolymer mortars demonstrate very promising performances, having obtained a high mechanical resistance and a good adhesion to concrete. On the other hand the adhesion between CFRP and geopolymer mortars proved to be smaller than expected which could be due, to the fact that the composition of the mortar was not optimized or even to the nature of the CFRP.
\end{abstract}

\section{Introduction}

Geopolymeric binders appear to be an alternative to ordinary Portland cement (OPC), due to high mechanical performances and environmental advantages. According to some authors [1] durability is the most important issue on determining the success of these new materials. Geopolymeric binders generates $80 \%$ less carbon dioxide than Portland cement [1]. Weil et al. [2] mentioned that in comparison to OPC concrete the global warming potential (GWP) of geopolymeric concrete is $70 \%$ lower. The cost of geopolymeric based concrete is one of the major factors which still remains a severe disadvantage over Portland cement based concrete explaining why this new product is not yet a current alternative [3-5].

Torgal et al. [6-8] show that geopolymeric mortars based on tungsten mine wastes can be as much as 7 times cheaper than current commercial repair mortars. But if the cost to bond strength ratio were compared the differences are even higher, with the cost of the cheapest commercial repair mortar being 13,8 times higher than the geopolymeric mortars. A new development in the repair and strengthening of reinforced concrete systems is the use of carbon fiber reinforced polymers (CFRP) strips bonded to concrete substrate with epoxy resins. This method is a relatively new retrofitting method, developed first in Japan [9,10]. Epoxy adhesive being used in the construction industry is very sensitive to temperature variations. Both experimental and finite element results show that the epoxy temperature should not exceed $70{ }^{\circ} \mathrm{C}$ in order to maintain the integrity between the CFRP and concrete [11]. It is noted that frequently exposure to direct sunlight causes temperatures higher than $70{ }^{\circ} \mathrm{C}$ which causes malfunction CFRP. This means that adhesive materials that remain stable with higher temperatures are needed. Since geopolymers are known to possess high stability at high temperature, these materials can be an alternative to epoxy resins. This 
papers presents results about the concrete retrofitting using of metakaolin based geopolymers mortars.

\section{Experimental work}

Materials. Geopolymer mortars. The metakaolin used in this study was subject to a thermal treatment at $650{ }^{\circ} \mathrm{C}$ during a few seconds using a flash calcination apparatus.

Geopolymeric mortars were a mixture of aggregates, metakaolin, calcium hydroxide and alkaline silicate solution. The factors analysed were, aggregate/binder mass ratio $(30 \%, 60 \% ; 90 \%)$, sodium hydroxide concentration $(12 \mathrm{M}, 14 \mathrm{M}, 16 \mathrm{M})$ and the percentage substitution of metakaolin by calcium hydroxide in the mixture $(5 \%, 10 \%)$.

The use minor calcium hydroxide percentages improve the compressive strength of geopolymeric mortars [6]. The explanation for that is related to the formation of two different phases, geopolimeric gel and calcium silicate hydrates, being that the former acts as microaggregates [12]. The alkaline activator was prepared prior to use. An activator with sodium hydroxide and sodium silicate solution $\left(\mathrm{Na}_{2} \mathrm{O}=13.5 \%, \mathrm{SiO}_{2}=58.7 \%\right.$, and water $\left.=45.2 \%\right)$ was used with a mass ratio of 1:2.5. Previous investigations showed that this ratio lead to the highest compressive strength results in alkali-activated mortars [6]. The sand, metakaolin and calcium hydroxide were dry mixed before added to the activator.

OPC concrete substrate. Concrete slabs were cast into moulds with $300 \times 200 \times 50 \mathrm{~mm}$ $\left(\mathrm{fc}_{28 \mathrm{~d}}=20 \mathrm{MPa}\right)$. As for beams they have $850 \times 100 \times 80 \mathrm{~mm}$. The concrete specimens were cured immersed in water during 28 days. This curing period provides an almost complete concrete hydration as old concretes in field practice. Workability of the fresh concrete was measured with a standard slump cone (NP EN 12350-2, 2002) immediately after mixing and a slump of $30 \mathrm{~mm}$ was obtained.

Commercial repair mortars. Two commercially available repair materials which are labelled R1 and R2 were also used in this study. The repair materials are supplied as pre-packed blend of graded aggregates with a maximum size $2 \mathrm{~mm}$, cement, silica fume, fibres and other additives. A water/powder ratio of 0.16 is recommended for use in material R1 and 0,14 for R2.The typical density of the fresh material is $2100 \mathrm{Kg} / \mathrm{m}^{3}$. The repair products are ready for on-site mixing and use, requiring only the addition of clean water. Table 3 presents the properties of the two commercial repair mortars as well as their adhesion strength obtained in the pull-off test for 14 and 28 curing days.

\section{CFRP sheets and epoxy adhesive}

CFRP sheets were provided in rolls by BASF and were composed by unidirectional carbon fibres with a commercial reference MBrace CF130. The medium viscosity epoxy adhesive used to bond the CFRP strips to concrete is a two components system (resin and hardener) with a commercial reference MapWrap 31. After mixing the two components the mixtures remains workable during 40 minutes at $23{ }^{\circ} \mathrm{C}$.

\section{OPC concrete specimen preparation}

The process starts with surface roughening operations to remove grease, oils, free particles, laintance and also producing a irregular surface. Then a geopolymeric mortar are applied followed by the CFRP sheets with $800 \mathrm{~mm}$ and a second layer of geopolymeric mortar.

\section{Test procedures}

Compressive and flexural strength testing. Compressive and flexural strength data of geopolimeric mortars was obtained using $160 \times 40 \times 40 \mathrm{~mm}^{3}$ cubic specimens according to EN 101511. The fresh mortar were cast and allowed to set at room temperature for $24 \mathrm{~h}$ before being 
removed from the moulds and kept at room temperature $\left(20{ }^{\circ} \mathrm{C}\right)$ until tested in compression and flexural strength. Compressive strength for each mortar mixture was obtained from an average of at least 3 specimens. Flexural strength of concrete specimens uses $850 \times 100 \times 80 \mathrm{~mm}$ beams reinforced by CFRP sheets and is done according to NP EN 12390-5. The flexural tests were conducted with an electro-hydraulic universal testing machine, at a controlled rate of axial displacement. The supports were placed $25 \mathrm{~mm}$ from the beginning of the beams. Table 4 shows the characteristics of the concrete beams tested.

Table 4 - OPC concrete beams characteristics

\begin{tabular}{|c|c|c|c|c|}
\hline \multirow{2}{*}{ Ref } & Description & \multicolumn{2}{|c|}{ Geopolymeric mortar composition } \\
\cline { 3 - 5 } & & $\begin{array}{c}\text { Sodium } \\
\text { hydroxide } \\
\text { concentration }\end{array}$ & $\begin{array}{c}\text { Calcium hydroxide } \\
\text { content } \\
(\%)\end{array}$ & $\begin{array}{c}\text { Sand/binder } \\
\text { mass ratio } \\
(\%)\end{array}$ \\
\hline CFRP0 & Plain concrete & - & - & - \\
\hline CFRP1 & $\begin{array}{c}\text { Concrete reinforced with CFRP } \\
\text { and epoxy adhesive }\end{array}$ & - & - & - \\
\hline CFRP2 & $\begin{array}{c}\text { Concrete reinforced with CFRP } \\
\text { and geopolymeric mortar }\end{array}$ & $14 \mathrm{M}$ & 10 & 60 \\
\hline CFRP3 & CFRP5 & & & \\
\hline
\end{tabular}

Pull-off. The adhesion strength was assess by pull-off test according to EN 1015-12. This test uses a Proceq Dyna Z15 device and a epoxi adhesive with a commercial reference Icosit K101.The adhesion strength was obtained from an average of 6 pull-off test specimens.

\section{Results and discussion}

Compressive and flexural strength testing of geopolymeric mortars. Figure 1 presents the results of the compressive strength according to the curing days for geopolymeric mortar mixtures with several sodium hydroxide concentrations and several sand/binder mass ratios.
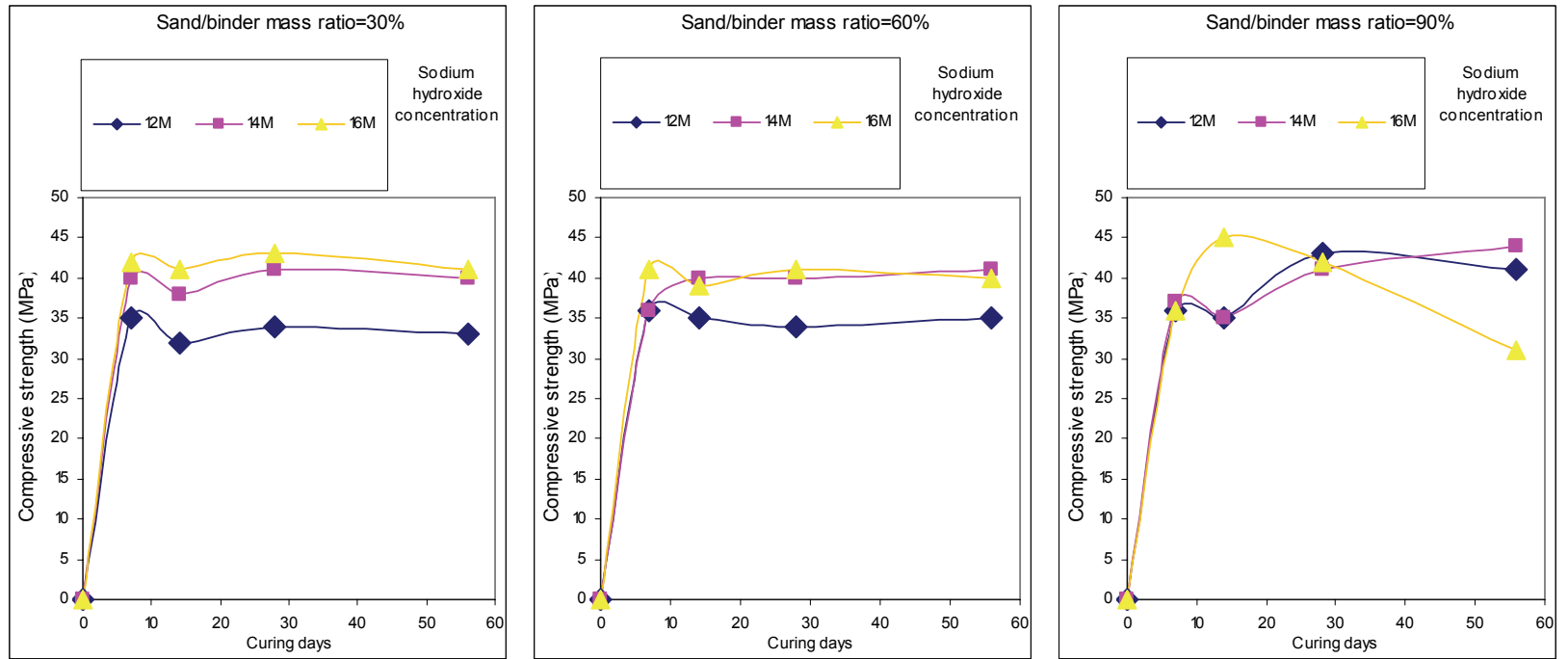

Figure 1 - Compressive strength according to curing days for geopolymeric mortar mixtures with several sodium hydroxide concentrations $(12 \mathrm{M}, 14 \mathrm{M}, 16 \mathrm{M})$ and several sand/binder mass ratios $(30 \% ; 60 \%, 90 \%)$

The coefficient of variation was lower than $15 \%$. After 7 days curing all the mixtures present a compressive strength above $30 \mathrm{MPa}$. The results show that higher sodium hydroxide concentrations lead to a compressive strength increase, but that only happens beyond 7 days curing. Higher 
concentrations of alkaline solution raises the $\mathrm{pH}$ which increases the dissolution and solubility of the aluminosilicate mineral waste and provides positive ions to balance the negative charge of the aluminate group [13,14]. The adverse effect reported by Lee et. al. [15] related to reduction in strength due to excess of alkali have not been confirm with the exception of the mixture containing a sodium hydroxide concentration of $16 \mathrm{M}$ and a sand/binder mass ratio of $90 \%$. Figure 2 shows the compressive strength versus $\mathrm{H}_{2} \mathrm{O} / \mathrm{Na}_{2} \mathrm{O}$ atomic ratio according to curing days for geopolymeric mortars with several sand/binder mass ratios.
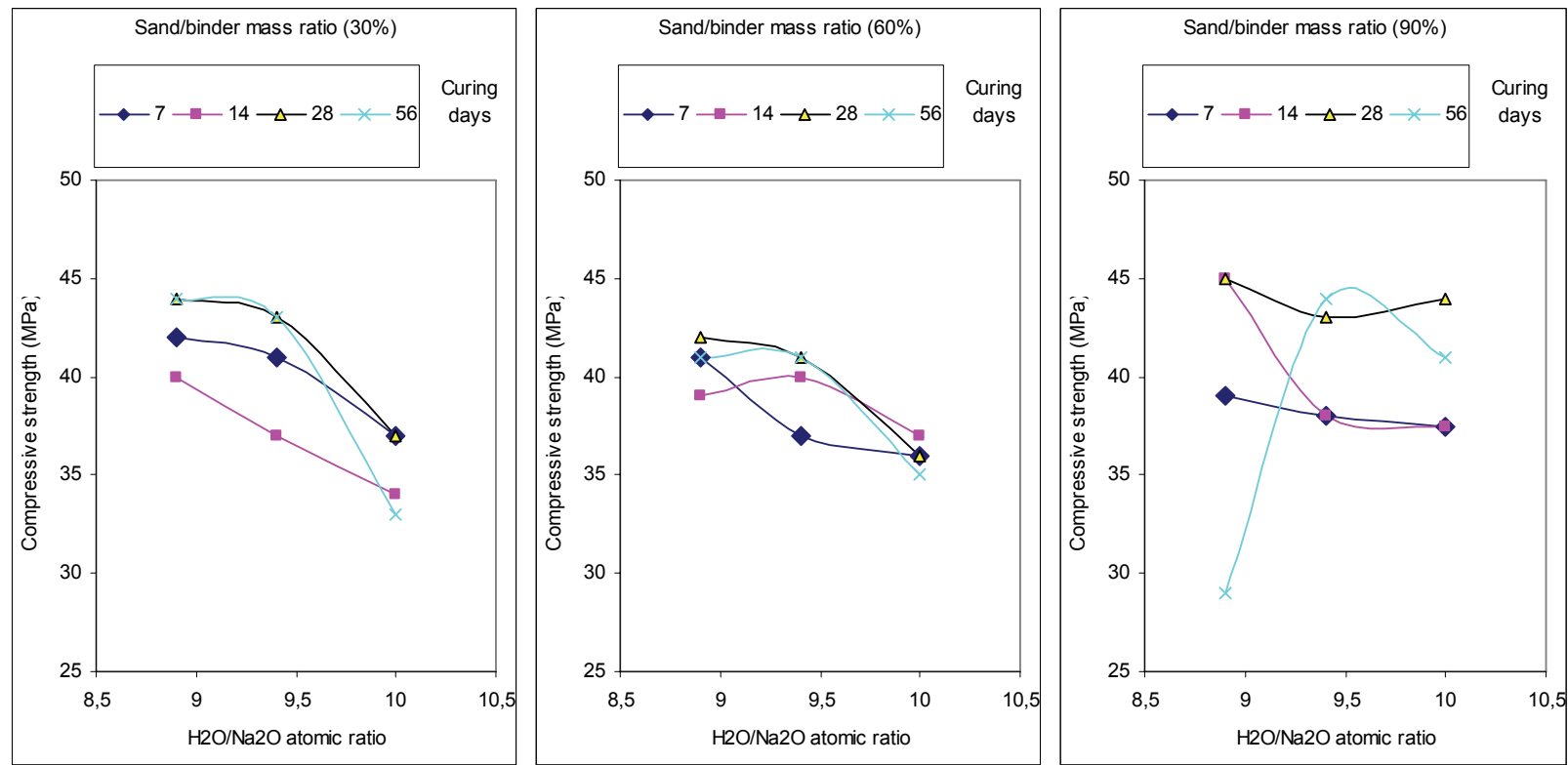

Figure 2 - Compressive strength versus $\mathrm{H}_{2} \mathrm{O} / \mathrm{Na}_{2} \mathrm{O}$ atomic ratio according to curing days for geopolymeric mortars with several sand/binder mass ratio $(30 \% ; 60 \%, 90 \%)$

Although other authors [6] obtained a lower compressive strength for the same sodium hydroxide concentration and calcium hydroxide content (30MPa for $16 \mathrm{M}$ and $10 \%$ lime), when using tungsten mine waste mud the explanation for that is not entirely related to the different reactivity between the metakaolin and the tungsten mine waste mud. The different results are much more related to the $\mathrm{H}_{2} \mathrm{O} / \mathrm{Na}_{2} \mathrm{O}$ parameter which is $8.9(16 \mathrm{M})$ in the present study and was 13,4 for those authors. Flexural strength results are present in Figure 3.
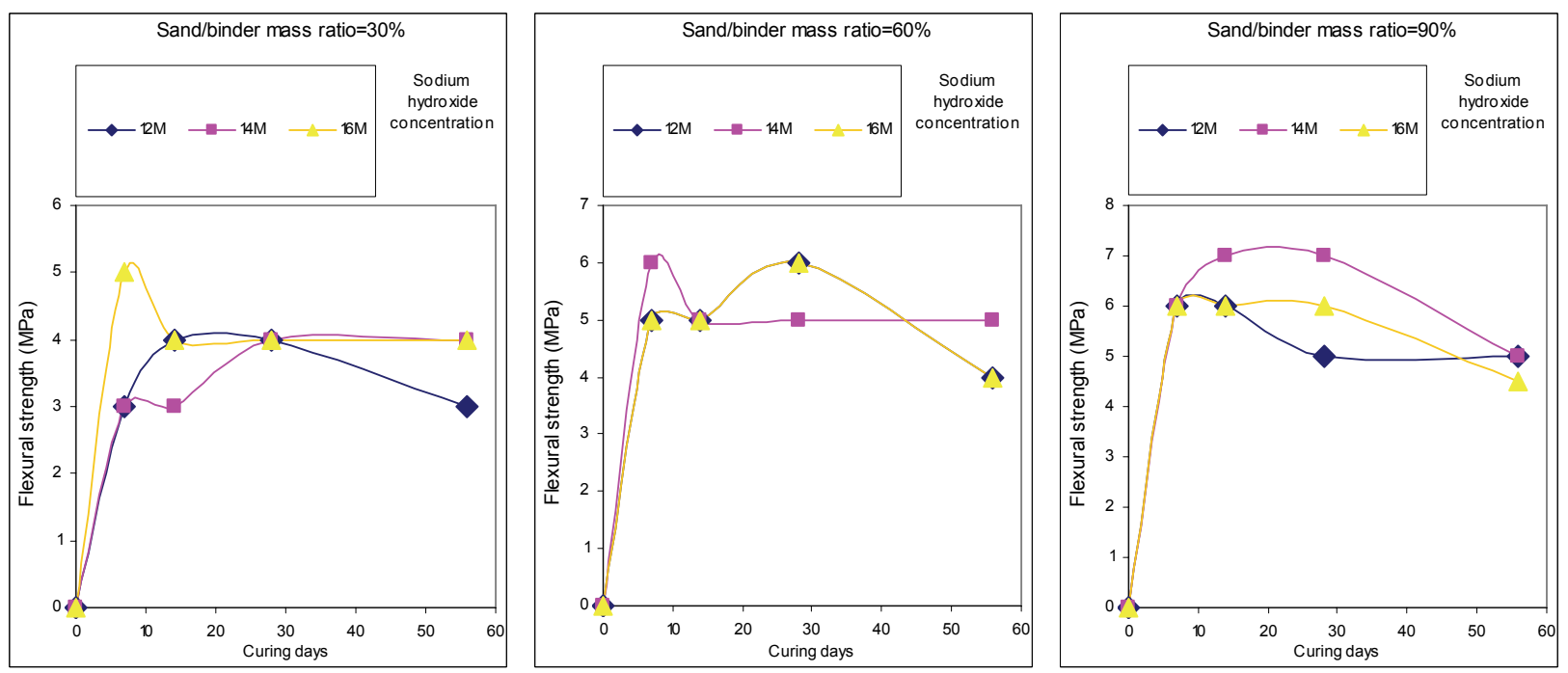

Figure 3 - Flexural strength according to curing days for geopolymeric mortar mixtures with several sodium hydroxide concentrations $(12 \mathrm{M}, 14 \mathrm{M}, 16 \mathrm{M})$ and several sand/binder mass ratio $(30 \% ; 60 \%, 90 \%)$ 
The results represent $10-15 \%$ of the compressive strength. This is quite similar to the behavior observed for ordinary Portland cement based concrete. Similar findings were reported by others using fly-ash based geopolymeric binders [16]. However, Torgal et al [17] reported a $\mathrm{ft} / \mathrm{fc}$ ratio around $20-25 \%$ for tungsten mine waste based geopolymeric mortars. The flexural strength loss with curing time observed in several mixtures, is probably due to the fact that CSH reaction and the geopolimeric reaction will compete against each other for soluble silicates, and give rise to a binder composed of two porous phases which leads to strength loss [18,19]. An alternative explanation is related to the possibility of the occurrence of shrinkage cracking near the aggregates, originating a clear tensile strength reduction [20], that could only be confirmed when shrinkage and tensile strength were studied. And a third explanation is related to the formation of gel similar to the one that takes place in ASR of portland cement binders, so that the gel volume increase would explain strength loss.

Geopolymeric mortars used as adhesive for CFRP. The pull-off strength results were all below $0.2 \mathrm{MPa}$. The explanation is probably related to the shrinkage behavior of the metakaolin mortars. Another explanation maybe due to the fact that the geopolymeric mortar mixture was not optimized. Also this CFRP sheets probably are not the best option for this purpose. Further investigations in order to find the best CFRP sheets to be used with geopolymeric binders are needed. As for the flexural strength of concrete beams reinforced with CFRP sheets (Figure 4), the results confirm that using a epoxy adhesive (FRP1) is a better option to insure the adhesion between concrete and FRP compared to use of geopolymeric mortars.

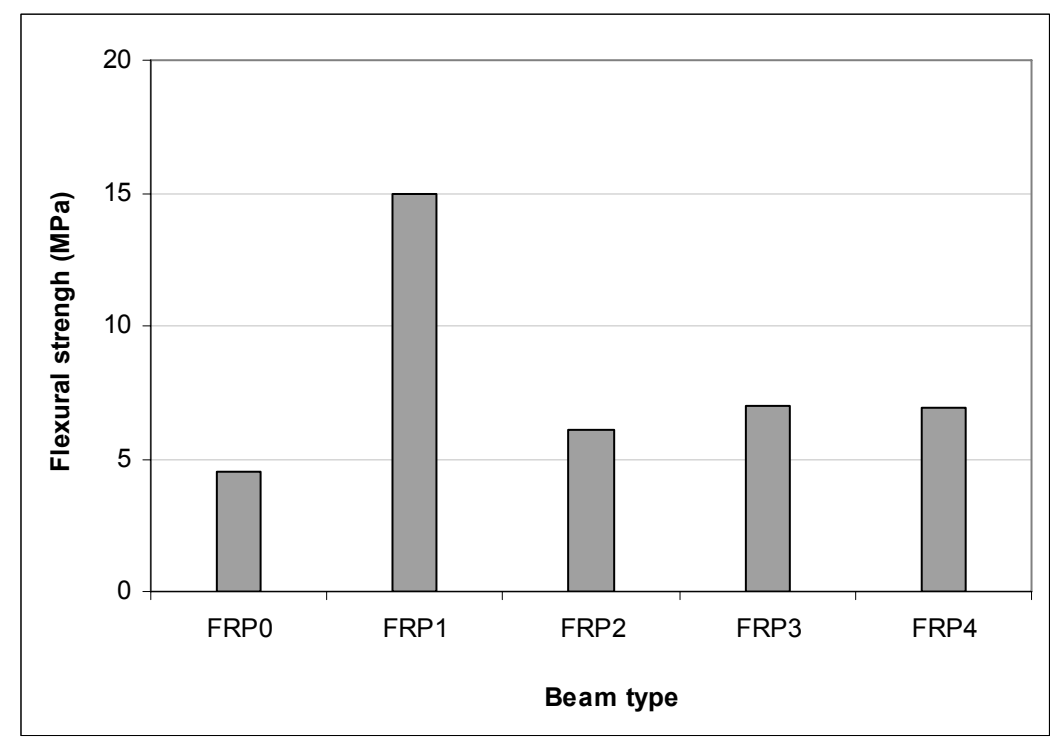

Figure 11 - Flexural strength of OPC concrete beams reinforced with geopolymeric mortars and CFRP

\section{Conclusions}

One of the largest disadvantages of geopolymeric binders is that they are more expensive than Portland cement based ones. The explanation for their high cost lies essentially in the cost of the chemical activators. This context show us that for the time being investigations should focus on high cost applications such as concrete repair materials. Based on the experimental results the following conclusions can be drawn. Metakaolin geopolimeric mortars with low sand/binder mass ratio present low adhesion to concrete substrate due to high shrinkage behaviour deduced by the microcracks in the surface of the specimens. Although the mortars tested show adhesion strength lower than the commercial repair mortars the former are much more cost-effective (5 to 10 times less expensive). Further investigations in order to find optimized mortar compositions and the appropriate CFRP sheets to insure maximum adhesion are still needed. 


\section{References}

[1] P. Duxson, J. Provis, G. Lukey, S.J.S Van Deventer, The role of inorganic polymer technology in the development of green concrete, Cement and Concrete Research 31 (2007) 1590-1597.

[2] M. Weil, K. Dombrowski, A. Buchawald, Life-cycle analysis of geopolymers, In Geopolymers, Structure, Processing, Properties and Applications, ISBN -13: 978184569449 4, Ed. J. Provis \& J. Van Deventer, Woodhead Publishing Limited Abington Hall, Cambridge, UK: 2009, pp.194-210.

[3] J. Davidovits, Chemestry of geopolymeric systems. Terminology, In Proceedings of 99 Geopolymere Conference 1 (1999) 9-40.

[4] S.J.S. Deventer, Opportunities ans obstacles in the commercialisation of geopolymers. Geopolymer 2002, Melbourne.

[5] R. Harper, W. South, R. Knigth, Geopolymers - a commercial reality? In proceedings of 2002 Geopolymer Conference. Melbourne, Australia.

[6] F. Pacheco-Torgal, J.P. Gomes, S. Jalali, Investigations on mix design of tungsten mine waste geopolymeric binders, Construction and Building Materials 22, 2008, 1939-1949.

[7] F. Pacheco-Torgal; J.P. Gomes, S. Jalali, Tungsten mine waste geopolymeric binders. Preliminary hydration products, Construction and Building Materials 23 (2009) 200-209.

[8] F. Pacheco-Torgal, J.P. Gomes, S. Jalali, Adhesion characterization of tungsten mine waste geopolymeric binder. Influence of OPC concrete substrate treatment, Construction and Building Materials 22 (2008) 154-161.

[9] H. Fukuyama, S. Sugano, Japanese seismic rehabilitation of concrete building after the Hyogoken Nanbu Earthquake, Cement Concrete Composites 22 (2000) 59-79.

[10] A. Badanoiu, J. Holmgren, Cementitious composites reinforced with continuous carbon fibres for strengthening of concrete structures, Cement \& Concrete Composites 25 (2003) 387-394

[11] J.C.P.H. Gamage, R. Al-Mahaidi , M.B. Wong, Bond characteristics of CFRP plated concrete members under elevated temperatures, Composite Structures 75 (2006) 199-205.

[12] C. Yip, G. Lukey, S.J.S. Deventer, The coexistence of geopolymeric gel andcalcium silicate hydrate gel at the early stage of alkaline activation, Cement and Concrete Research 35 (2005) 1688-1697.

[13] U. Rattanasak, P. Chindaprasirt, Influence of $\mathrm{NaOH}$ solution on the synthesis of fly ash geopolymer, Minerals Engineering, 22 (2009) 1073-1078.

[14] P. Chindaprasirt, C. Jaturapitakkul, W. Chalee, U. Rattanasak, Comparative study on the characteristics of fly ash and bottom ash geopolymers, Waste Management 29 (2009) 539543.

[15] W. Lee, J. S.J. Van Deventer, The effects of inorganic salt contamination on the strength and durability of geopolymers, Colloids and Surfaces 211 (2002)115-126.

[16] B. Rangan, Engineering properties of geopolymer concrete. In Geopolymers, Structure, Processing, Properties and Applications, ISBN -13: 978184569449 4, Ed. J. Provis \& J. Van Deventer, Woodhead Publishing Limited Abington Hall, Cambridge, UK, 2009, pp.211-226.

[17] F. Pacheco-Torgal, J.P. Gomes, S. Jalali, Investigations about the effect of aggregates on strength and microstructure of geopolymeric mine waste mud binders, Cement and Concrete Research 37 (2007) 933-941.

[18] G. Xiaolu, S. Huisheng, A. Warren, Compressive strength and microstructural characteristics of class C. Fly ash geopolymer, Cem Concr Comp 2 (2010) 142-147.

[19] P. De Silva, K. Sagoe-Crenstil, V. Sirivivatnanon, Kinetics of geopolymerization: Role of $\mathrm{Al}_{2} \mathrm{O}_{3}$ and $\mathrm{SiO}_{2}$, Cem Concr Res 37 (2007) 512-518.

[20] J. Wongpa, K. Kiattikomol, C. Jaturapitakkul, P. Chindaprasirt, Compressive strength, modulus of elasticity, and water permeability of inorganic polymer concrete, Materials and Design 31 (2010) 4748-4754. 